\title{
Analisis pengaruh citra perusahaan dan kualitas layanan terhadap loyalitas pelanggan melalui kepuasan pelanggan
}

\author{
Bambang \\ Fakultas Bisnis, Institut Teknologi Dan Bisnis Kalbis \\ Triyono Arief Wahyudi* \\ Fakultas Bisnis, Institut Teknologi Dan Bisnis Kalbis
}

Paper type

Research paper
Keywords: corporate image, service quality, customer satisfaction, customer loyality variable with 2 sub model using SPSS. The result from this study shows that there is a significant effect between corporate image to costumer satisfactory, a significant effect between quality of service to costumer satisfactory, and also a significant effect between costumer satisfactory to costumer loyalty. Therefore, Team Wound, PT XYZ Jakarta and Bekasi needs to perform effective activities and to always up to date periodically so that the costumers are more loyal to use its products.

\begin{abstract}
Abstrak
Penelitian ini bertujuan untuk mengetahui pengaruh citra perusahaan dan kualitas layanan terhadap loyalitas pelanggan serta dampaknya pada kepuasan pelanggan.Penelitian ini menggunakan metode kuantitatif dengan 100 responden di Jakarta dan Bekasi.Metode yang dipakai adalah regresi dan korelasi dari masing masing variable dengan 2 sub model menggunakan SPSS.Hasil dari penelitian ini menunjukkan terdapat pengaruh signifikan antara citra perusahaan terhadap kepuasan pelanggan, terdapat pengaruh signifikan antara kualitas layanan terhadap kepuasan pelanggan, juga terdapat pengaruh signifikan antara kepuasan pelanggan terhadap loyalitas pelanggan. Oleh sebab itu Team Perawatan Luka PT XYZJakarta dan Bekasi perlu melakukan kegiatan - kegiatan yang efektif dan selalu di up date perkebangannya secara berkala agar pelanggannya lebih loyal menggunakan produknya.
\end{abstract}

*Email korespondensi: triyono.wahyudi@kalbis.ac.id

Pedoman Sitasi: Bambang, \& Wahyudi, T.A. (2019). Analisis pengaruh citra perusahaan, dan kualitas layanan terhadap loyalitas pelanggan melalui kepuasan pelanggan. Jurnal Manajemen Strategi dan Aplikasi Bisnis, 2(1), 61 - 70
Received: 15 Jan 2019

Accepted: 25 Feb 2019

Online: 08 Mar 2019

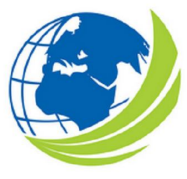

\author{
Jurnal Manajemen \\ Strategi dan Aplikasi \\ Bisnis, Vol 2, No.1, April \\ 2019, pp. 61 - 70 \\ eISSN2655-237X
}




\section{PENDAHULUAN}

Industri bahan bangunan (building material) merupakan salah satu industri yang memberikan kontribusi cukup besar untuk perekonomian Indonesia serta mengalami pasang surut karena sangat terkait dengan perkembangan industri lain seperti industri properti seperti perumahan tapak (landed house), rumah susun (apartement) dan gedung perkantoran (high rise), dan juga dari sektor pemerintah seperti pembangunan infrastruktur seperti: bendungan, bandara, pelabuhan dan lain sebagainya.

Industri properti dalam hal ini, jika dibandingkan dengan pembangunaninfrastruktur lebih berdampak secara langsung terhadap industri bahan bangunan utamanya industri papan gypsum. Data dari Bank Indonesia yang dirilis dalam situs resminya www.bi.go.id menjelaskan bahwa indeks harga properti nasional pada triwulan ke II 2017 tumbuh sebesar 0,03\% (qtq) melambat dibanding triwulan sebelumnya sebesar 3,02\% (qtq). Sedangkan secara tahunan terjadi kenaikan menjadi 2,79\% (yoy) dibanding 2,69\% (yoy) pada triwulan I tahun 2017. Indeks pasokan properti komersial secara triwulan tumbuh sebesar $0,10 \%$ (qtq) melambat dibandingkan 0,59\% (qtq) pada triwulan sebelumnya. Sedangkan indeks permintaan terhadap sektor properti komersial pada triwulan II 2017 juga mengalami perlambatan dari 0,04\% (qtq) menjadi 0,23\% (qtq). Perkembangan indeks harga properti komersial dari tahun 2015 sampai dengan 2017 secara triwulanan dapat dilihat pada gambar 1.1 berikut ini.

Papan gypsum sendiri merupakan material penutup plafon yang telah menjadi salah satu pilihan utama konsumen dewasa ini.Selain papan gypsum kita mengenal beberapa material lain seperti papan triplek, papan silikat dan papan GRC.Industri papan gypsum sendiri sudah berkembang lebih dari 2 dasawarsa di Indonesia.Adalah Jayaboard (sekarang Sheetrock) dari USG Boral yang pertama kali beredar di pasar gypsum Indonesia. Setelah Jayaboard beberapa merek mulai masuk ke industri ini, seperti Thai Gypsum, CSR, namun seiring dengan krisis ekonomi pada tahun 1998 kedua merek tersebut tidak eksis lagi di pasar. Peluang pasar papan gypsum di Indonesia sendiri masih sangat besar, dibanding dengan beberapa negara tetangga kita, www.kompas.com menginformasikan bahwa tingkat konsumsi perkapita gypsum dalam meterpersegi adalah 0,4 , hal ini juga dapat dilihat pada situs resmi www.boral.co.au di segmen management presentations.

Dari segi brand image, menurut survey yang dipublikasikan oleh Topbrand-award.com pada tahun 2015, Jayaboard masih merupakan merek dengan brand image paling tinggi di mata konsumen. Hal ini dapat dimengerti karena sejarahnya Jayaboard merupakan merek gypsum board yang pertama kali masuk ke Indonesia dan mereka dengan cerdik menggandeng Grup Ciputra dengan grup kontraktor Jaya sehingga sampai sekarang hampir semua sektor dari arsitek sampai ke kontraktor mengenal merek ini. Tingkat brand awareness Jaya board mencapai $36 \%$, sedangkan Elephant gypsum ada di posisi kedua yaitu 14,6\%, hal ini masih menjadi pekerjaan rumah bagi Elephant gypsum bagaimana meningkatkan brand awareness mereka di mata konsumen serta mengejar ketertinggalan dibandingkan dengan pesaing terdekat mereka yaitu Jayaboard. Persepsi konsumen akanbrand image Elephant diakui memang sudah cukup baik, namun masih tertinggal dibandingkan dengan brand image Jayaboard.

Dari segi value, atau secara ringkas dapat dijabarkan bagaimana benefit versus sacrifice dari pelanggan Elephant gypsum dibandingkan dengan pemimpin pasar seperti Jayaboard. Pemain di industri ini sama halnya dengan pemain di industri bahan bangunan lain menggunakan jalur distribusi dari level distributor, whole saler, dan pengecer, di mana setiap level ada tipe toko khusus gypsum dan toko bahan bangunan. Di mana di setiap level memiliki tingkat persepsi akanvalue yang berbeda beda. Pemain di level yang lebih di bawah contoh toko 
bangunan, relatif akan lebih sulit dipuaskan dibandingkan pemain yangdi level di atasnya contoh whole saler gypsum board. Toko bangunan memiliki karakteristik menjual produk dengan banyak sekali item dan lebih ke tingkat eceran.Mereka banyak berhubungan dengan banyak distributor atau bahkan dengan principal dengan berbagai keuntungan yang ditawarkan sehingga terbiasa membandingkan.Dalam hal ini value dari Elephant gypsum di mata pelanggan merupakan hal menarik untuk diteliti.Seberapa tinggi nilai atau value dari Elephant gypsum di mata konsumen mereka.

Dari tinjauan segi kualitas produk hampir semua produk merek papan gypsum global yang masuk ke Indonesia memiliki kualitas yang baik.Namun dalam hal persepsi kualitas harus diakui bahwa pandangan konsumen pada umumnya masih melihat Jayaboard sebagai produk yang berkualitas paling baik di antara semua merek yang beredar di pasar.Hal ini menjadi tantangan tersendiri bagi Elephant gypsum untuk menilai seberapa jauh persepsi kualitas Elephant gypsum di mata pelanggan mereka.Apakah setelah sekian lama eksis di industri gypsum, Elephant memiliki persepsi kualitas yang baik di mata pelanggan.

Dari segi promosi dapat dikatakan bahwa hampir semua merek papan gypsum mengadakan promosi penjualan. Tentunya biaya yang dikeluarkan tergantung dari seberapa besar anggaran promosi yang dimiliki oleh masing - masing perusahaan. Tak terlepas Elephant gypsum juga mengadakan promosi penjualan selama ini dengan berbagai macam variasi promosi dan juga sasaran yang berbeda - beda. Sejauh mana persepsi pelanggan dari Elephant gypsum akan promosi penjualan yang dilakukan akan mempengaruhi tingkat kepuasan serta bagaimana dampaknya terhadap loyalitas pelanggan merupakan hal yang menarik untuk diteliti.

Muara dari beberapa variabel di atas adalah seberapa jauh pengaruh variabel - variabel tersebut terhadap kepuasan pelanggan Elephant gypsum serta bagaimana dampaknya terhadap tingkat loyalitas dari pelanggan elephant gypsum terhadap merek ini. Meskipun papan gypsum pada dasarnya dikategorikan ke dalam produk komoditas karena keterbatasan ragam produk, jika dibandingkan dengan sesama bahan bangunan seperti keramik yang lebih condong sebagai produk fashion, karena banyak ragam dan corak, merek merek yang ada tetap melakukan kegiatan promosi baik above the line maupun below the line, membangun brand image, menjaga kualitas produk dan menjaga nilai (value) untuk mencapai kepuasan konsumen. Hal inilah yang mendasari analisis peneliti bahwa ada pengaruh dengan mengetahui bagaimana pengaruh faktor faktor tersebut terhadap customer satisfaction dan selanjutnya faktor terakhir berpengaruh terhadap customer loyalty terhadap merek Elephant Gypsum maka diharapkan Elephant Gypsum dapat mengambil kebijakan yang tepat dalam memenangkan persaingan.

\section{KAJIAN PUSTAKA}

Pemasaran

American Marketing Association Board of Directors memberikan definisi pemasaran sebagai aktivitas, kumpulan institusi, dan proses untuk menciptakan, mengkomunikasikan, menyampaikan, dan pertukaran penawaran yang bernilai bagi pelanggan, klien, mitra, dan masyarakat luas (Disetujui Juli 2013, American Marketing Association). Tidak jauh berbeda, Kotler dan Armstrong (2012:29) suatu proses di mana perusahaan menciptakan nilai yang lebih untuk konsumen dalam rangka mendapatkan penghargaan atau nilai lebih dari konsumen sebagai imbalannya.

Customer Loyalty

Dalam persaingan yang sangat ketat, di mana selalu muncul pesaing baru, salah satu kunci untuk bertahan dan memenangkan persaingan adalah bagaiman membuat pelanggan menjadi setia atau 
loyal. Oleh karena itu dimensi customer satisfaction, efisiensi, pangsa pasar, riset, loyalitas pelanggan, retensi pelanggan, zero defection dan life long customer harus menjadi fokus perusahaan.

Menurut Don Peppers dan Martha Rogers dalam Kottler dan Keller (2009:134), satu - satunya nilai yang dapat diciptakan oleh perusahaan adalah nilai dari pelanggan dan merupakan nilai yang perusahaan miliki sekarang dan di masa yang akan datang. Suatu bisnis dapat dikatakan berhasil jika berhasil mendapatkan, mempertahankan dan bahkan menumbuhkan jumlah pelanggan.Pelanggan adalah sumber kehidupan perusahaan, semua yang aktivitas yang dilakukan oleh perusahaan pada dasarnya adalah berpusat pada pemenuhan kebutuhan pelanggan.Tanpa pelanggan kita tidak memiliki bisnis.

Loyalitas pelanggan merupakan perilaku untuk melakukan pembelian secara berulang ulang dan untuk membangun kesetiaan pelanggan terhadap suatu produk atau jasa yang dihasilkan oleh perusahaan tersebut membutuhkan waktu yang lama melalui suatu proses yang berulang ulang (Musanto 2004:128).

Brand image dan Loyalitas Konsumen

Brand image merupakan representasi dari merek yang telah dibangun oleh perusahaan di masa sebelumnya. Brand image yang baik dibangun dalam waktu yang sangat lama, sehingga perusahaan harus menjalankan strategi untuk mempertahankan brand image yang baik sehingga tidak mempengaruhi pelanggan untuk berpindah ke merek lain. Citra merek telah dibahas sebagai konsep penting dalam pemasaran sejak 1950-an; Namun, konsep ini belum mendapatkan consensus dari berbagai literature. Sejumlah peneliti mengkonseptualisasi citra merek sebagai kesan total suatu merek, termasuk pemikiran yang berkaitan dengan atribut produk, penggunaan produk, dan iklan. Peneliti lain telah menekankan manfaat simboliknya, seperti peningkatan harga diri dan status sosial, yang berasal dari kepemilikan merek (Cho et al., 2015). Literatur pemasaran yang lebih baru telah menekankan penggabungan dimensi emosional dengan dimensi kognitif dari citra merek (Keller, 1993 dan Cho et al., 2015), brand dinyatakan gabungan dari asosiasi merek, termasuk atribut (terkait produk dan nonproduk), manfaat (fungsional, simbolik, pengalaman), dan sikap.

Beberapa penelitian telah menyebutkan bahwa brand image merupakan faktor penting dalam membentuk keputusan pembelian (Wulandari \& Iskandar, 2018; Leksono \& Herwin, 2017) dan loyalitas konsumen (Hengestu \& Iskandar, 2017).

Perceived value

Menurut Zeithaml (1998) seperti yang dikutip oleh Aulia et al (2016) persepsi nilai merupakan penilaian konsumen secara holistik dari suatu produk berdasarkan dari persepsi apa yang diterima dan apa yang diberikan. Dapat diringkas sebagai berikut: Perceived value $=$ (Perceived benefit)/ (Perceived sacrifice)

Komponen yang diterima dapat diartikan sebagai manfaat yang diterima ketika konsumen menggunakan produk kita dan komponen yang diberikan dapat diartikan sebagai pengorbanan yang harus diberikan oleh pelanggan baik berupa aspek ekonomi maupun non ekonomi. Persepsi nilai dapat dideskripsikan ke empat dimensi yaitu:

1. Nilai harga rendah.

2. Nilai dari apapun yang konsumen inginkan dari suatu produk.

3. Nilai dari kualitas dari harga yang dibayarkan oleh konsumen.

4. Nilai dari apa yang didapat dari nilai yang diberikan perusahaan.

Menurut Dodd dan Monroe (1985) seperti yang dikutip oleh Chi (2015) dalam model harga, kualitas dan persepsi nilai, menjelaskan bahwa persepsi nilai menjadi faktor penting bagi konsumen untuk melakukan keputusan pembelian dan konsumen akan membeli suatu produk dengan persepsi nilai yang tinggi. 
Perceived quality

Persepsi kualitas dapat diartikan sebagai persepsi pelanggan terhadap keseluruhan kualitas atau keunggulan suatu produk atau jasa layanan berkaitan dengan apa yang diharapkan oleh pelanggan. Karena persepsi kualitas merupakan persepsi dari pihak pelanggan, maka tidak dapat ditentukan secara obyektif. Persepsi pelanggan akan melibatkan apa yang dirasakan penting oleh pelanggan karena setiap pelanggan memiliki kepentingan (yang diukur secara relatif) yang berbeda - beda terhadap suatu produk atau jasa (Durianto, 2004:96).

Persepsi kualitas merupakan hal yang wajar yang dirasakan oleh pelanggan ketika membeli suatu produk atau jasa.Apakah sesuai dengan harapan atau tidak.Persepsi kualitas di sini merupakan kualitas yang terkandung dalam produk yang digunakan oleh pelanggan. Menurut American Society for Quality Control dalam Kotler dan Keller (2009:143) kualitas adalah totalitas fitur dan karakteristik produk atau jasa yang tergantung pada kemampuannya untuk memuaskan kebutuhan yang tersirat maupun nyata. Persepsi kualitas merupakan elemen kunci dalam proses pengambilan keputusan pembelian oleh pelanggan di mana pelanggan akan membandingkan berbagai alternatif pilihan kualitas dalam rentang harga yang sesuai dengan kemampuan mereka ( Yee dan San, 2011). Menurut Aaker (1996) seperti yang dikutip oleh Saleem et al (2015) persepsi kualitas memprediksi level kualitas dari keseluruhan produk. Dalam penelitiannya Saleem et al (2015) menemukan bahwa persepsi kualitas produk berdampak langsung pada keputusan pembelian.

Perceived promotion

Menurut Moore dan Pareek (2006:85) promosi adalah elemen dalam marketing mix yang dapat memberikan good publicity dan brand equity produk atau jasa perusahaan. Menurut Zeithtml dan Bitner yang dikutip Ratih Hurriyati (2008:50) promotion adalah suatu unsur yang digunakan untuk memberitahukan dan membujuk pasar tentang produk dan jasa yang baru pada perusahaan melalui iklan, penjualan pribadi, promosi penjualan maupun publikasi agar konsumen yang lainnya sadar dan tertarik dengan penawaraan perusahaan. Menurut Elliot (2011:23) promosi adalah suatu kegiatan pemasaran yang membuat konsumen potensial, partner dan lingkungan menyadari dan tertarik pada penawaran yang diberikan oleh perusahaan.

Gilbert dan Jackaria (2002) seperti yang dikutip oleh Meo et al (2014) promosi penjualan terdiri dari berbagai macam strategi promosi jangka pendek yang dimaksudkan untuk meningkatkan keinginan untuk membeli dari pelanggan. Promosi penjualan merupakan penawaran khusus dan merupakan bagian dari kegiatan pemasaran suatu perusahaan. Promosi penjualan dan informasi harga meningkatkan persepsi akan harga dan motivasi pelanggan dalam membeli produk kita.

Customer satisfaction

Customer satisfaction menjadi salah satu tujuan penting dalam aktifitas berbisnis, dipandang sebagai salah satu indikator terbaik untuk meraih laba di masa yang akan datang. Peta persaingan bisnis semakin tajam, preferensi dan perilaku pelanggan berubah, teknologi informasi berkembang dengan cepat mendorong organisasi bisnis untuk lebih menanggapi customer satisfaction untuk menjamin keberlanjutan bisnis. Customer satisfaction adalah konsumen yang merasa puas pada produk atau jasa yang dibeli dan digunakannya kembali dan akan kembali menggunakan produk dan jasa yang ditawarkan (Zeithhaml dan Bitner: 2003). Menurut Caditte et al yang dikutip oleh Tijptono (2006:19) customer satisfaction adalah perasaan yang timbul setelah mengevaluasi pengalaman memakai produk.

Menurut Tse dan Wilson yang dikutip oleh Tjiptono (2006:169) customer satisfaction merupakan respon pelanggan terhadap evaluasi persepsi atas perbedaan antara harapan awal sebelum pembelian atau standar kinerja lainnya dan kinerja aktual produk sebagaimana dipersepsikan setelah memakai atau mengkonsumsi produk yang bersangkutan. 
Menurut Fornel yang dikutip oleh Tjiptono (2006:169) customer satisfaction adalah evaluasi purna beli keseluruhan yang membandingkan persepsi terhadap kinerja produk dengan ekspetasi pra pembelian. Menurut Hill et al yang dikutip oleh Tjiptono (2006:169) customer satisfaction adlaah ukuran kinerja produk total sebuah organisasi dibandingkan serangkaian keperluan pelanggan.

Hipotesa

Berdasarkan uraian di atas maka hipotesis dalam penelitian ini adalah :

H1 : Brand image berpengaruh positif dan signifikan terhadap customer satisfaction.

H2 : Perceived value berpengaruh positif dan signifikan terhadap customer satisfaction.

H3 : Perceived quality berpengaruh secara positif dan siginifikan terhadap customer satisfaction.

H4 : Perceived promotion berpengaruh positif dan signifikan terhadap customer satisfaction.

H5 : Customer satisfaction berpengaruh positif dan siginifikan terhadap customer loyalty.

\section{METODE PENELITIAN}

\section{Data}

Dalam hal pengumpulan data dan sebagai kelengkapan penelitian, peneliti memperoleh informasi, data, petunjuk serta bahan-bahan pendukung lainnya dengan menggunakan sumber data primer. Data primer menurut Sugiyono (2016 : 137) adalah sumber data yang langsung memberikan data kepada pengumpulan data. Pada penelitian ini data yang diperoleh berupa data kuesioner yang disebarkan secara langsung ke responden.Kuesioner kemudian diukur dengan menggunakan skala likert.

Populasi dan Sampel

Populasi di artikan sebagai wilayah generalisasi yang terdiri atas objek atau subjek yang mempunyai kualitas dan karakteristik tertentu yang ditetapkan oleh peneliti untuk di pelajari kemudian dan di tarik kesimpulannya (Sugiyono 2016:115).Berdasarkan teori tersebut maka populasi pada penelitian ini adalah pelanggan Elephant Gypsum yang tersebar di Jabodetabek dan terdiri dari toko gypsum, toko bangunan, aplikator dan kontraktor.Sampel adalah sebagian dari populasi (Sugiyono, 2014:297).Teknik sampling yang digunakan adalah non-probability sampling dengan jenis sampling judgement. Menurut Sugiyono (2016:154), non-probability sampling adalah teknik pengambilan sample yang tidak memberi peluang atau kesempatan sama bagi setiap unsur atau anggota populasi untuk dipilih menjadi sampel. Dalam penelitian ini peneliti memilih responden yang merupakan pelanggan Elephant Gypsum yang sudah pernah membeli produk lebih dari 3 kali di Elephant Gypsum. Oleh karena populasi tidak diketahui, penelitian ini menggunakan rumus pengambilan sampel menurut Ferdinand (2006) menyatakan bahwa: bila ukuran sampel terlalu besar maka model menjadi sangat sensitive sehingga sulit mendapatkan goodness of fit yang baik. Untuk itu ukuran sampel dalam penelitian ini menggunakan rumus jumlah indikator 5-10 kali jumlah indikator dari keseluruhan variabel latin.

\section{Teknik analisis}

Teknik analisis pada penelitian ini menggunakan uji analisis jalur (path analysis) dengan metode regresi linear berganda; dan uji statistik parametrik, yaitu uji t (parsial).

\section{HASIL DAN PEMBAHASAN}

\section{Gambaran Umum Responden}

Berdasarkan hasil penelitian yang dilakukan dengan menyebarkan kuesioner kepada responden yang menjadi pelanggan Elephant Gypsum di Jabodetabek, didapatkan data rata-rata responden sebanyak 168 orang (93,3\%) merupakan pelanggan Elephant Gypsum yang sudah lebih dari tiga kali membeli produk Elephant Gypsum, sedangkan 12 orang (6,67\%) merupakan pelanggan elephant gypsum yang kurang dari tiga kali membeli produk elephant gypsum. Artinya mayoritas responden 
didominasi pada pelanggan yang sudah membeli produk elephant gypsum sebanyak lebih dari tiga kali.

Berdasarkan karakteristik responden menurut tipe pelanggan diperoleh hasil responden dari toko gypsum sebanyak 95 orang $(52,27 \%)$, diikuti dengan tipe pelanggan toko bangunan sebanyak 56 orang (31,11\%), tipe pelanggan Aplikator sebanyak 14 orang $(7,77 \%)$, dan yang terakhir tipe pelanggan kontraktor sebanyak 15 orang (8,33\%). Dapat disimpulkan bahwa sebagian besar responden terdapat pada tipe pelanggan dari toko gypsum.

Uji Asumsi Klasik

Penelitian ini menggunakan model analisis regresi, sebelum analisis dilakukan maka terlebih dahulu kuesioner memenuhi uji asumsi atau pengujian persyaratan analisis regresi. Berikut urutan pengujian asumsi persyaratan analisis regresi:

Uji Normalitas. Penelitian ini menggunakan analisis gambar histogram dan normal P-P Plot untuk uji normalitasnya. Berdasarkan analisa gambar plot dan grafik histogram model regresi antara variabel brand image, perceived valueperceived quality dan perceived promotion telah memenuhi asumsi normalitas.Begitu pula dengan variabel customer satisfaction terhadap customer loyalty telah memenuhi asumsi normalitas.

Uji heteroskedastisitas, bertujuan untuk menguji apakah dalam model regresi terjadi ketidaksamaan variance dari residual satu pengamatan ke pengamatan yang lain. Berdasarkan hasil analisis uji heterokedastisitas terhadap kedua sub model, variabel brand image,perceivedvalue, perceived quality dan perceived promotion terhadap customer satisfaction dan customer satisfaction terhadap customer loyalty bahwa tidak terjadi heteroskedastisitas dalam penelitian ini.

Uji Autokorelasi, merupakan korelasi pada tempat yang berdekatan datanya yaitu cross sectional. Autokorelasi merupakan korelasi time series (lebih menekankan pada dua data penelitian berupa data rentetan waktu). Pada penelitian ini, uji autokorelasi dibagi menjadi dua metode pendektesi yaitu sub model 1 menggunakan metode durbin Watson dan sub model 2 menggunakan metoderun test. Hasil uji autokorelasi pada sub model pertama, tabel Durbin Watson menunjukkan angka 1,788. Di mana nilai Durbin Watson sebesar 1,890 lebih besar dari 1,788 dan kurang dari 4-du yaitu 4-1,788 = 2.212. Sedangkan hasil uji autokorelasi pada sub model kedua menujukkan bahwa, nilai Asymp.Sig (2-tailed) sebesar 0,061 lebih besar dari 0,05. Sehingga hasil uji autokorelasi terhadap kedua sub model tersebut dapat disimpulkan tidak ada masalah atau gejala auto korelasi.

Uji t

Untuk mengetahui ada tidaknya pengaruh variabel independen terhadap variabel dependen, maka dilakukan pengujian terhadap hipotesis yang diajukan pada penelitian ini.Metode pengujian terhadap hipotesis yang diajukan dilakukan pengujian menggunakan uji t dan analisis jalur.

Tabel 1 Ringkasan Pengujian Variabel Independen Terhadap Variabel Dependen (Secara Parsial)

\begin{tabular}{|c|c|c|c|c|}
\hline Variabel Penelitian & t Hitung & t Tabel & Signifikansi & Kesimpulan \\
\hline Brand image & 3.726 & \multirow{5}{*}{1.973} & .000 & Signifikan \\
\hline Perceived value & 3.500 & & .001 & Signifikan \\
\hline Perceived quality & 2.906 & & .004 & Signifikan \\
\hline Perceived promotion & 5.918 & & .000 & Signifikan \\
\hline Customer satisfaction & 13.228 & & .000 & Signifikan \\
\hline
\end{tabular}

Sumber: Data primer, diolah 2017

Berdasarkan tabel diatas hubungan antarabrand image,perceivedvalue, perceived quality dan perceived promotion terhadap customer satisfaction adalah : 
Variabel Brand Image berpengaruh secara signifikan dan positif terhadap Customer Satisfication karena nilai ( $p$ value $0.000>0.05 / t$ hitung $3.726>t$ tabel 1,973).Brand image juga menjadi variabel yang paling berpengaruh terhadap customer satisfication.Hasil ini juga didukung dengan penelitian Radita Herliza dan Marheni Eka Saputri (2016) yang menjelaskan bahwa brand image dapat membuat konsumen mengenal dan mengevaluasi kualitas dari produk tersebut.Dari hasil penelitiannya ditemukan hubungan yang positif antara brand image dan customer satisfaction.

Variabel Perceived Value berpengaruh secara signifikan dan positif terhadap Customer Satisfication karena nilai ( $\mathrm{p}$ value $0.000>0.05 / \mathrm{t}$ hitung 3.500 $>\mathrm{t}$ tabel 1,973).Perceived value juga menjadi variabel yang paling berpengaruh terhadap customer satisfication. Hasil ini juga didukung dengan penelitian Mitha Novenscha Vidya (2015) dalam penelitiannya menjelaskan bahwa perceived value berpengaruh signifikan terhadap customer satisfaction, semakin baik persepsi nilai konsumen terhadap produk kita semakin tinggi tingkat kepuasan konsumen.

Variabel perceived quality berpengaruh secara signifikan dan positif terhadap Customer Satisfication karena nilai ( $\mathrm{p}$ value $0.000>0.05 / \mathrm{t}$ hitung $2.906>\mathrm{t}$ tabel 1,973). Perceived quality juga menjadi variabel yang paling berpengaruh terhadap customer satisfication.Hasil ini juga didukung dengan penelitian dari Fanny Fibriyanti Salim dan Diah Dharmayanti, S.E., M.Si. (2014) yang dalam penelitiannya menyebutkan bahwa perceived quality berpengaruh positif terhadap customer satisfaction. Di mana dijelaskan bahwa perceived quality yang semakin tinggi berpengaruh positif terhadap customer satisfaction.

Variabel perceived promotion berpengaruh secara signifikan dan positif terhadap customer satisfication karena nilai ( $\mathrm{p}$ value $0.000>0.05 / \mathrm{t}$ hitung $5.918>\mathrm{t}$ tabel 1,973 ). Perceived promotion juga menjadi variabel yang paling berpengaruh terhadap customer satisfication.Hasil ini juga didukung dengan penelitian dari Endang Tjahjaningsih yang mejelaskan bahwa semakin tinggi persepsi promosi semakin pula tingkat kepuasan konsumen.Promosi produk atau jasa membantu membangun hubungan dengan konsumen.Semakin baik penerimaan promosi yang dilakukan oleh perusahaan dan membentuk persepsi promosi makan semakin tinggi tingkat kepuasan.

Variabel customer satisfaction berpengaruh secara signifikan dan positif terhadap customer loyalty karena nilai ( $\mathrm{p}$ value $0.000>0.05 / \mathrm{t}$ hitung 13,228 >t tabel 1,973).Customer satisfaction juga menjadi variabel yang paling berpengaruh terhadap customer loyalty.Hasil ini juga didukung dengan penelitian dari Faizan Mohsan (2011), bahwa ada pengaruh yang sangat siginifikan antara customer satisfaction dengan customer loyalty di mana penelitian di sektor perbankan.Semakin tinggi tingkat customer satisfaction, maka semakin tinggi tingkat customer loyalty.

Dari hasil di atas dapat dinyatakan bahwa brand image,perceivedvalue, perceived quality dan perceived promotion merupakan faktor-faktor utama yang dapat mempengaruhi dan meningkatkan customer satisfication. Hasil lainnya juga memperlihatkan bahwa customer satisficationmemberikan dampak yang positif dan berpengaruh secara signifikan terhadap customer loyalty.Hal tersebut menunjukan bahwa customer satisficationmenjadi salah satu faktor yang mempengaruhi customer loyalty.

\section{KESIMPULAN}

Berdasarkan hasil dari analisis diatas, maka dapat ditarik kesimpulan sebagaiberikut: pertama, dari keempat faktor, faktor-faktor tersebut secara keseluruhan berpengaruh signifikan terhadap customer satisfication. Kedua, customer satisficationberpengaruh secara signifikan dan memiliki dampak positif terhadap customer loyalty.Hal ini menunjukkan bahwa semakin baik manajemen Elephant Gypsummaka semakin meningkat dan mempertahankan customer satisfactiontersebut.

Implikasi temuan ini adalah pihak manajemen Elephant Gypsum perlu melakukan berbagai upaya untuk mempertahankan tingkat customer satisfaction seperti melakukan upaya promosi yang berkesinambungan, menjaga standar kualitas produk sesuai dengan standar acuan mutu internasional, menjaga brand image yang baik serta yang tak kalah penting adalah mempertahankan 
perceived value yang tinggi dari konsumen Elephant Gypsum di mana konsumen merasa harga atau effort yang dikeluarkan sesuai dengan barang yang didapat. Jika aspek - aspek tadi diperhatikan maka niscaya tingkat customer loyalty Elephant Gypsum akan tinggi. Hal ini akan berdampak pada eksistensi Elephant Gypsum di industri papan gypsum pada jangka panjang.

Penelitian ini berhasil membuktikan kesluruhan hipotesis, sehingga penelitian mendatang disarankan untuk meneliti variabel - variabel lain seperti personal communication, sunk cost dan social behavior yang dapatmempengaruhi customer satisfaction serta customer loyalty.

\section{REFERENSI}

American Marketing Assocation (2013). "Definition Of Marketing”. [Online]. Diakses tanggal 23 Maret 2017 dari https:// ama.org/AboutAMA/pages/ Definition-of-Marketing.aspx

Departemen Statistik Bank Indonesia Sektor Riil (2017). "Perkembangan Properti Komersial”.[Online]. Diakses tanggal 25 Juni 2017 dari: http:// www.bi.go.id/id/publikasi/survei / propertikomersial/ Default.aspx

Investopedia.com (2017). ).“Business To Business - B To B" [Online].Diakses tanggal 8 Oktober 2017 dari http:// www.investopedia.com/terms/ b/ btob.asp

Investwords.com (2017)."B2B Defintion”.[Online].Diakses tanggal 8 Oktober 2017 dari http:// www.investorwords.com/364/B2B.html

Rougemont, F. D (2012)."Analyst and Investor Site Tour". [Online]. Diakses tanggal 23 Maret 2017 dari: http:// www.boral.com.au/ images/ common/ pdfs/ management-presentations/ Boral-Gypsum-AsiaPresentation.pdf

Cho, E., Fiore, A. M., \& Russell, D. W. (2015). Validation of a fashion brand image scale capturing cognitive, sensory, and affective associations: Testing its role in an extended brand equity model. Psychology \& Marketing, 32(1), 28-48.

Choy, J. Y., Ng, C. S. (2011). “Consumers' Perceived Quality, Perceived Value and Perceived Risk Towards Purchase Decision on Automobile".American Journal of Economics and Business Administration 3.

Chi, H. K., Dr. Yeh, H. R. dan Tsai, Y. C. (2015). ). "The Influences of Perceived Value on Consumer Purchase Intention: The Moderating Effect of Advertising Endorser". Jims journal.org.

Durianto, D. et al. (2004). Brand Equity Ten. Strategi Memimpin Pasar. Jakarta: PT. Gramedia Pustaka Utama.

Elliot, G., Sharyn, R. T., and Waller, D. (2012).Marketing, John Wiley and Sons.

Ferdinand, A. (2006). Metode Penelitian Manajemen. Semarang: Badan Penerbit Universitas Diponegoro.

Ghozali, I. (2011). Aplikasi Analisis Multivariate Dengan Program SPSS.Semarang. Badan Penerbit Universitas Diponegoro.

Hassan, R.S. et al. (2015). "Effect of Customer Relationship Management on Customer Satisfaction".Procedia Economics and Finance 23.

Herliza, R. dan Saputri, M. E. (2016). "Pengaruh Brand Image Terhadap Kepuasan Pelanggan,Studi pada Zara di Mall PVJ Bandung”. E-Proceeding of Management.Vol 3.Program Studi Administrasi Bisnis Fakultas Komunikasi dan Bisnis, Telkom University.

Hurriyati, R. (2010). Bauran Pemasaran dan Loyalitas Konsumen. Bandung: Alfabeta.

Kitchathorn, P. (2009). "Factor Influencing Customer Repurchase Intention: An Investigation of Switching Barriers that Influence the Relationship between Satisfaction and Repurchase Intention in the Low Cost airlines Industry in Thailand". School of Business Administration (DBA), University of South Australia International Graduate School of Management.

Kotler, P. dan Armstrong, G. (2013).Principles of Marketing.

Leksono, R. B., \& Herwin, H. (2017). PENGARUH HARGA DAN PROMOSI GRAB TERHADAP BRAND IMAGE YANG MEMPENGARUHI KEPUTUSAN PEMBELIAN KONSUMEN PENGGUNA TRANSPORTASI BERBASIS ONLINE. Jurnal Riset Manajemen dan Bisnis (JRMB) Fakultas Ekonomi UNIAT, 2(3), 381390.

Hengestu, N., \& Iskandar, D. A. (2017). Pengaruh Citra Merek Dan Harga Terhadap Loyalitas Pelanggan Air Minum Dalam Kemasan. Jurnal Riset Manajemen dan Bisnis (JRMB) Fakultas Ekonomi UNIAT, 2(3), 363-372.

Meo, A., et al. (2014), "The Impact of Promotional Tools on Sales Promotion".Journal of Public Administration and Governance, Macrothink Institute.

Mohsan, F. et al. (2011). "Impact of Customer Satisfaction on Customer Loyalty and Intentions to Switch: Evidence from Banking Sector of Pakistan”.International Journal of Business and Social Science. 
Musanto, T. (2004). "Faktor - Faktor Kepuasan Pelanggan Dan Loyalitas Pelanggan: Studi Kasus pada CV Sarana Media Advertising Surabaya". Jurnal Manajemen dan Kewirausahaan.

Moore, K. dan Pareek, N. (2006).Marketing the Basic.Routledge. $2^{\text {nd }}$ Edition.

Pearson. dan Keller, K.L. (2012). Marketing Management, Pearson.

Peppers, D. dan Rogers, M. (2009). Managing Customer Experience and Relationships: A Strategic Framework. 3rd Edition.Wiley.

Saleem, A. et al. (2015). "Product Perceived Quality and Purchase Intention With Consumer Satisfaction". Global Journal of Management and Business Research: E Marketing.

Salim, F.F \& Dharmayanti D, (2014).“Pengaruh Brand Image dan Perceived Quality Terhadap Kepuasan dan Loyalitas Pelanggan Mobil Toyota di Surabaya”.Jurnal Manajemen Pemasaran Petra Vol. 2, No. 1.

Sugiyono.(2013). Metode Penelitian Kuantitatif dan Kualitatif. Bandung: Alfabeta.

Rouse, M (2017).“Customer Relationship Management (CRM)”.[Online]. Diakses tanggal 6 Oktober 2017 dari http:// searchcrm.techtarget.com/ definition/ CRM

Tjahjaningsih, E. (2013). "Pengaruh Citra dan Promosi Terhadap Kepuasan Pelanggan Serta Dampaknya Terhadap Loyalitas Pelanggan (Studi Pada Pelanggan Supermarket Carrefour di Semarang)", Media Ekonomi dan Manajemen.Vol. 28.

Tjiptono, F. (2006).Manajemen Jasa. Edisi pertama. Yogyakarta: Andi.

Top Brand Award (2015)."Top Brand Survey" [Online]. Diakses tanggal 3 Oktober 2017 dari: http:// www.topbrand-award.com/top-brand-

survey/surveyresult/top brand index 2015 fase 1Vidya, M.N. (2014). "Analisis Pengaruh Customer Perceived Value Dan Corporate Brand Image Terhadap Customer Satisfaction Dan Dampaknya Pada Customer Loyalty Pada Majalah Infobank". Jurnal Bina Nusantara University.

Wijaya, T. B. (2009). Lifestyle Marketing. Paradigma Pemasaran Bisnis Jasa.

Wulandari, R. D., \& Iskandar, D. A. (2018). Pengaruh Citra Merek Dan Kualitas Produk Terhadap Keputusan Pembelian Pada Produk Kosmetik. Jurnal Riset Manajemen dan Bisnis (JRMB) Fakultas Ekonomi UNIAT, 3(1), 11-18.

Zeithhaml \& Bitner.(2003). Service Marketing Integrating Customer Focus Across The Firm.3rd edition. Boston: Mc Graw Hill/ Irwin.

\section{PROFIL PENULIS}

Bambang dan Triyono Arief Wahyudi merupakan mahasiswa dan dosen di Prodi Magister Manajemen, Fakultas Bisnis, Institut Teknologi Dan Bisnis Kalbis yang beralamat di Jl. Pulomas Selatan Kav. 22, Jakarta 13210 